\title{
Spitting behaviour in the Chinese cobra Naja atra
}

\author{
ALESSANDRO PATERNA
}

Via F. Brandimarte 3, Teramo 64100, Italy

Author e-mail: alessandro.paterna@hotmail.com

\begin{abstract}
This study describes the ability of a captive Chinese cobra (Naja atra) to spit venom and presents a video analysis of a strike and spit manoeuvre. However, among the many specimens of $N$. atra raised by the author only the female examined in this study regularly displayed spitting behaviour, and then only within the confines of its terrarium. Fang morphology of $N$. atra was investigated by microscopy and compared with that of a 'true' spitting cobra, Naja sputatrix. The results show that $N$. atra does not have specially modified fangs so that venom is ejected downwards from the fangs, not forwards. Consequently, to direct venom at a target requires a specific manoeuvre involving a forward lunge and head rotation. This arrangement is very similar to that described for Naja kaouthia and suggests that the evolution of spitting behaviour could precede the development of specialised fangs that refine the action.
\end{abstract}

\section{INTRODUCTION}

In Asia there are eleven cobra species belonging to the genus Naja (Wallach et al., 2009; Wüster, 1996). Most representatives of this group are 'spitters' having short tubular fangs at the front of the mouth with a peculiarity at the distal end of the fang that allows the snakes to spit venom forwards (Bogert, 1943; Triep et al., 2013; Wüster \& Thorpe, 1992; Young et al., 2004). The venom duct within the fang is modified so that at the lower front side of the fang there is a reduced orifice with the inner posterior side of the duct transversally angled to the length of the tooth. This arrangement enables the cobra to release venom jets at approximatively the angle at which the head is inclined.

Among the 'non-spitting' Asian cobras, two species have long been rumoured to be able to spit. One of them is the monocled cobra (Naja kaouthia, Lesson 1831) of which spitting behaviour has been recently formally documented (Santra \& Wüster, 2017). While the other is the Chinese cobra (Naja atra, Cantor, 1842), that was previously reported to be responsible for a case of conjunctival and corneal injury in a woman (Fung et al., 2010). In addition, prior literature has invoked N. atra as being able to spit its venom (Herklots, 1938; Reitinger \& Lee, 1978), albeit rarely, and lacking the precision of the true spitting cobras (Karsen, et al., 1986; Wüster \& Thorpe, 1992).

The subject of this study is an adult female Chinese cobra (Fig. 1) that was captive born in 2012 from a pair imported from Hong Kong in the early 2000s. This specimen is of the black banded phenotype (Fig. 1) which in recent years has manifested a special inclination to spit, the first photographic evidence is from February 2016.

\section{MATERIALS AND METHODS}

The female Chinese cobra (N. atra) used in the study was kept

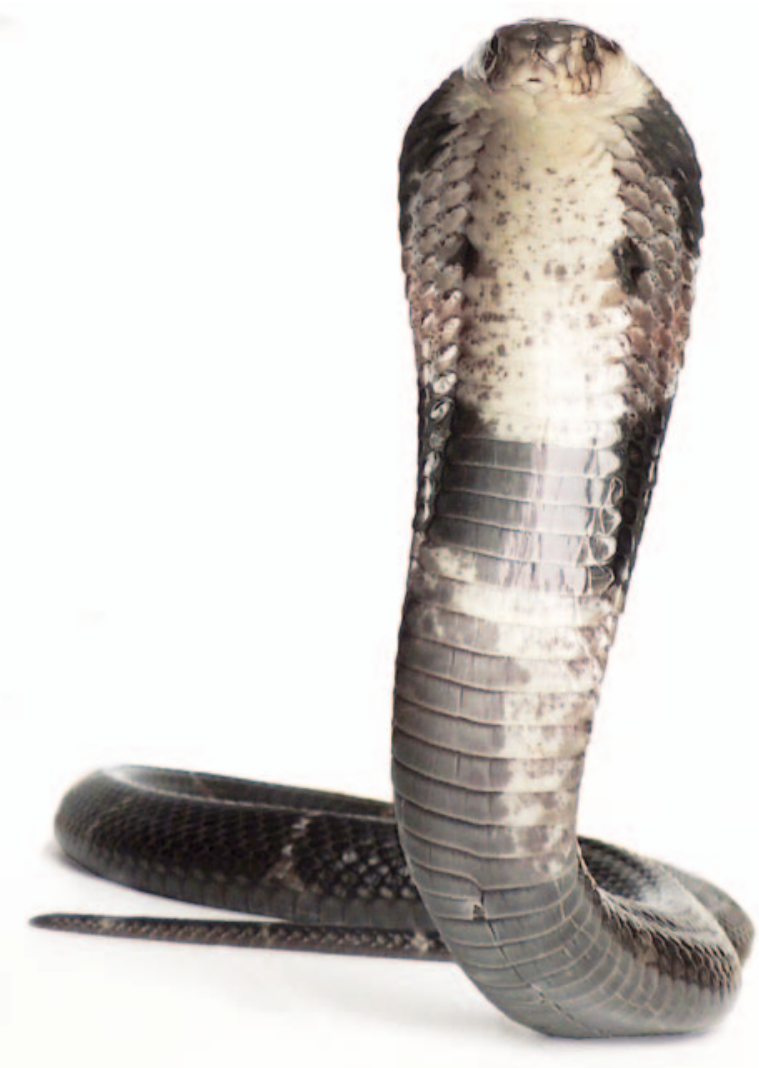

Figure 1. Adult female N. atra, the protagonist of this study (with a congenital groove in the ventral scales seen close to where the snake's body reaches the substrate)

in accordance with Italian law. It was raised in a controlled environment and treated with special care after its spitting behaviour was manifest. Details of the snake's lepidosis are presented in Supplementary Material (see p. 25). The snake measured about $100 \mathrm{~cm}$ (total length) and weighed $292 \mathrm{~g}$. It successfully bred and laid eggs in 2015, 2016 and 2018. To 
capture the specimen's spitting behaviour, a digital camera (Nikon Coolpix P510) was positioned inside her terrarium and set on to records video at 120 frames per second. To optimise the results captured by the lens, dark cardboard panels and additional lights were applied inside and outside the terrarium which measured $120 \mathrm{~cm}$ long, $60 \mathrm{~cm}$ deep and $50 \mathrm{~cm}$ high. To visualise the traces of venom following a spit, sheets of A4 paper of different colours (red, yellow, blue or green) were used as targets although no one colour caught the attention of the cobra more than another. Before each filming session, the glass front of the terrarium was removed and then, as soon as the cobra's attention had been caught by my person (full visor protection and protective gloves were used), a paper target was placed at the same height as the terrarium directly in front of the cobra. The maximum distance set between the terrarium and a target was $40 \mathrm{~cm}$.

For an examination of the fangs by microscope, a fang was collected directly from the mouth of one of the female's offspring (hatched 2016), sired by a male sibling from the same clutch. The fang was removed carefully from the live snake while no longer fixed to the maxillary bone. Microscope pictures of the fang were taken using a stereomicroscope (Nikon SMZ645). The sample was placed in a Petri dish containing distilled water, and the images were taken through the object when laid on a solid surface and also when suspended in distilled water. For comparative purposes, the same procedure was applied to the fangs of an adult female Indonesian spitting cobra Naja sputatrix, Boie, 1827 , collected from a deceased adult female bred in captivity (for details of the snake's lepidosis see Supplementary Material). Fang measurements were taken using a digital calliper (accuracy $\pm 0.005 \mathrm{~mm}$ ). Tinting of discharge orifices and venom canals in images of the fangs was possible due to the double illumination and the suspension of the fangs during microscopy. This technique conferred transparency to the fangs making the discharge orifices, venom canals and liquid within them clearly visible.

\section{RESULTS}

\section{Video recording of striking and spitting}

The data analysed and described here were collected from a single recording. However, numerous spitting events were captured (at total of 15 video clips were recorded over two days when the cobra exhibited the spitting behaviour in response to me coming too close to her terrarium), but only examples providing the clearest visual results were selected for analysis. The video selected had a duration of 16 minutes and 10 seconds, during which 33 spitting attempts were captured. Some of the examples of venom spitting were clearly visible to the naked eye, while others required the examination of single video frames. The time of the whole spitting action (time lapse calculated from the first frame in which the cobra moves forward to strike from its defensive posture to the beginning of the spit) varied from 0.76 to 1.16 seconds with an average of 0.97 seconds. The spitting time itself ranged from 0.03 to 0.13 seconds with an average of 0.07 seconds $(n=33)$. Observations were made of venom being spat from both fangs simultaneously and from a single fang. The venom traces from a single fang were generally linear and following a spit from a distance of about 0-20 cm ranged from $5.8 \mathrm{~cm}$ to $10.5 \mathrm{~cm}$ wide. When two fangs were used the trace covered an area of up to $7.7 \mathrm{~cm}$ wide and 8.9 $\mathrm{cm}$ high (Fig. 2).

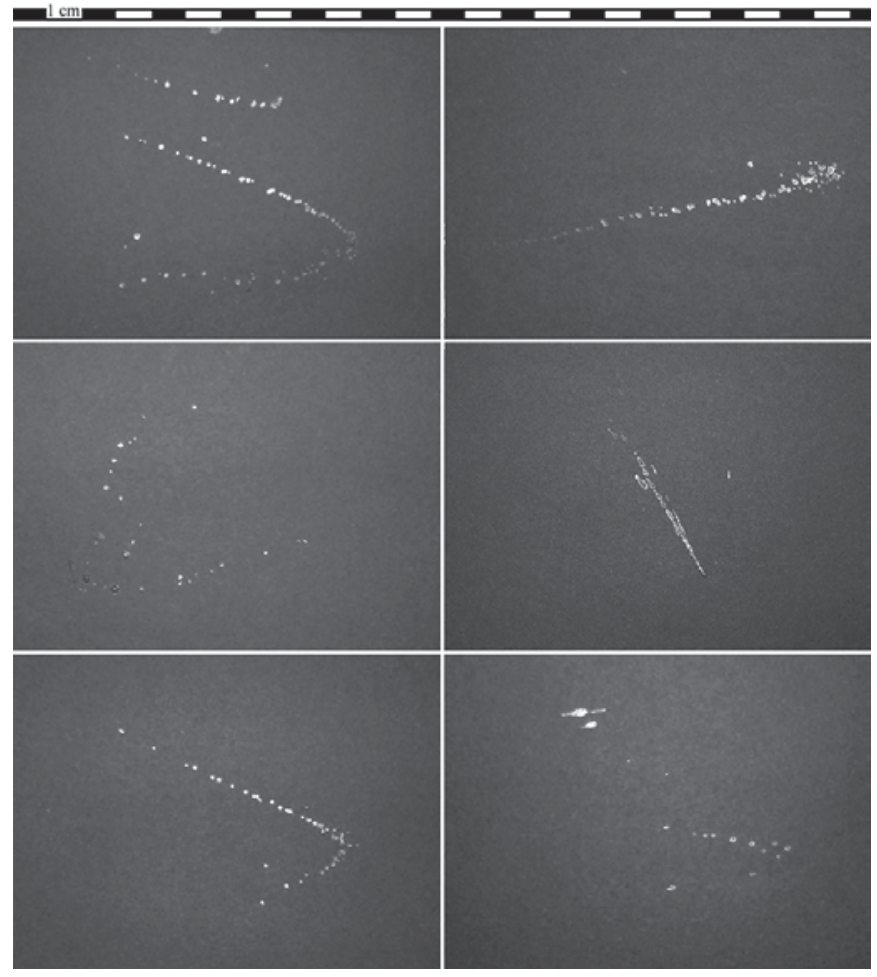

Figure 2. Venom traces on coloured paper from a series of consecutive spits by the female $N$. atra, presented chronologically from left to right, top to bottom. The first, third and sixth images are traces made by venom jets from two fangs, the others are from a single fang.

\section{Fang analysis}

Microscope pictures show the venom canal follows the length of the fang, leading straight to its tip (Fig. 3). The placement of the discharge orifice corresponds to $27.53 \%$ of the total fang length (measurement from the fang tip to the basal orifice). This fang morphology is comparable to that of non-spitting cobras (Bogert, 1943). In contrast, the fang of the spitting species $N$. sputatrix shows the discharge orifice in the frontal wall of the fang at $9.18 \%$ of its total length. Furthermore, the venom canal and its shape are clearly visible, as are the reduced orifice size and the angle leading to it (Fig. 3), which presents an inclination of about $110^{\circ}$.

\section{Spitting manoeuvre}

The cobra started most of her defensive actions from the 'hooding' posture (Fig. 4a). From that position it throws itself in a frontal thrust against the target, opening her mouth during the manoeuvre (Fig. 4b). When the forward projecting movement results in the body reaching an inclination to the ground of about $45^{\circ}$, the cobra pulls its head backwards, inclining the nape until the cranium axis is perpendicular to the ground (Fig. 4c). In that position, with the venom fangs aligned in parallel with the ground and the discharge orifice oriented towards the target, the snake releases a stream of 
a) N. atra

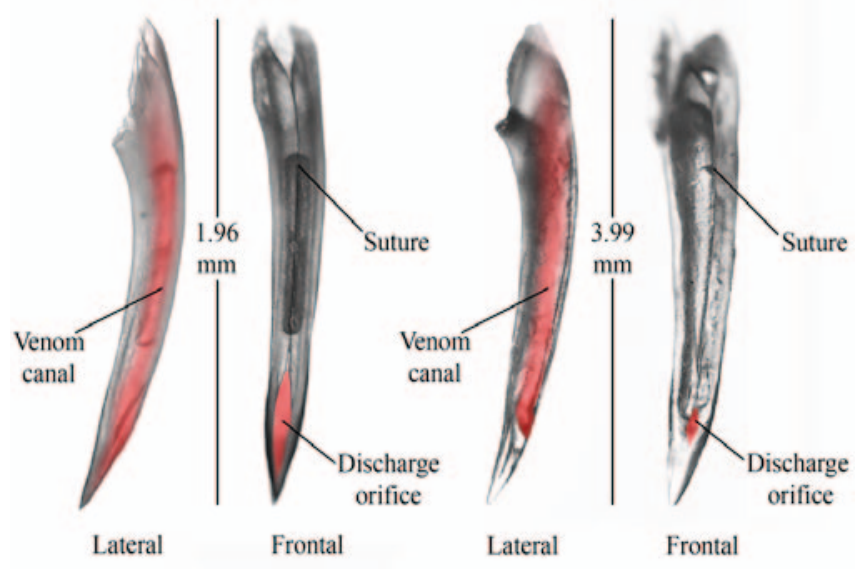

Figure 3. Lateral and frontal views of N. atra and N. sputatrix fangs, with venom canals and discharge orifices highlighted, following terminology of Bogert (1943), Wüster and Thorpe (1992)

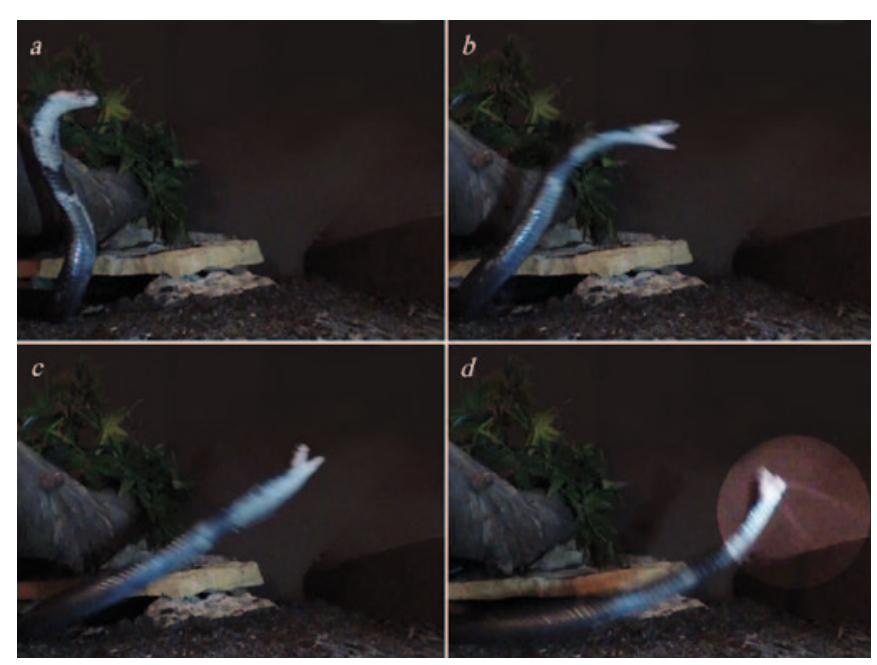

Figure 4. A spitting manoeuvre by the female $N$. atra that was completed in a total of 0.866 seconds (i.e. the time lapse between frames a. to d.)

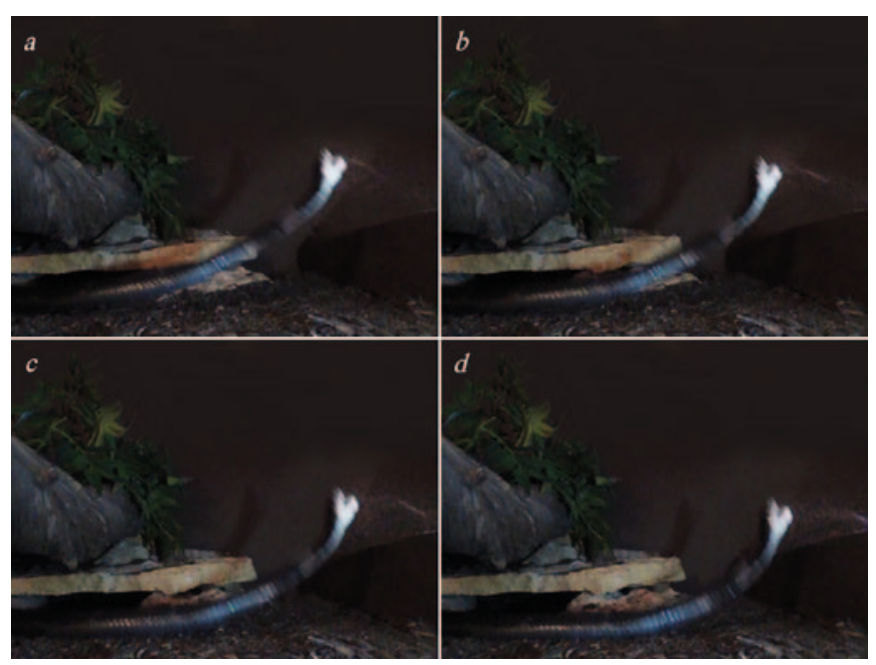

Figure 5. A venom spit by the female $N$. atra that was completed in a total of 0.083 seconds (i.e. the time lapse between frames a. to d.) venom towards the target (Fig. 4d; Fig. 5). After the spitting event, the cobra keeps its head angled backwards $\left(\sim 90^{\circ}\right)$, until its body hits the ground. In very few cases, the specimen has been observed to spit directly from the hooding posture without the forward thrust.

\section{DISCUSSION}

This study confirms that the Chinese cobra ( $N$. atra) can spit venom. However, among the many specimens raised by the author, and 18 offspring bred in captivity of the same bloodline, the female examined in this study was the only one to spit regularly. In addition, the observed defensive technique was shown only when the cobra was inside her terrarium. Once extracted from the terrarium, the cobra completely lost her defensive temperament. Nonetheless, venom spitting is performed by this individual almost every time a figure is perceived close to the front of the terrarium, and this behaviour has been observed repeatedly within a short period. While the quantity of venom ejected from each fang was variable, the shapes and characteristics of venom imprint are similar to those produced by 'true' spitting cobras featuring modified fangs (Young \& O'Shea, 2005; Young et al., 2009).

As shown from the microscope pictures, the fang of the Chinese cobra presents a linear canal and a large discharge orifice. The morphology of the venom duct does not allow the specimen to spit frontally, as do the typical spitting species of the same genus. Thus, differences in the fang structure between $N$. atra and the spitting $N$. sputatrix are evident (Fig. 3). The discharge orifice of the fang of the Indonesian spitting cobra exhibits smaller dimensions and is located on an upper position on the frontal side of the tooth, distant from its tip. Comparing the size of the fang orifice in the two species as a proportion of total fang length, that of N. atra accounts for $33.3 \%$ which is three times bigger than that of N. sputatrix. In Figure 3, the angle of the venom canal of $N$. sputatrix is easily recognisable, which, together with the reduced dimensions of its outlet, enables the cobra to spit forward and for notable distances.

Given the fang morphology of the Chinese cobra, in order to spit it must incline its head backwards to about $90^{\circ}$. The act of spitting itself is executed in a very brief time, consisting of few hundredths of a second, while the whole manoeuvre of the spitting behaviour typically takes place in less than one second. However, compared to the 'true' spitters of the same genus, the venom jets seem to be able to reach only a relatively short distance. Moreover, the nature of this way of spitting is less precise than that of 'true' spitting species (this was also observed and reported in Karsen, et al., 1986). Reclining the head backwards to perform a horizontal spit, the cobra successfully directs the venom jets straight to the target, but it aim seems to lack precision in the vertical axis. In all the spitting recorded, the curvature of the venom spit is downward with respect to the fang inclination (Fig. 4 \& 5). This same characteristic has been described for $N$. kaouthia by Santra and Wüster (2017) and was predicted by Bogert (1943). The fang structure and striking manoeuvre that accompanies spitting described here for $N$. atra are 
both very similar to those described for $N$. kaouthia (Santra \& Wüster, 2017; Rasmussen et al., 1995). This suggests that the evolution of spitting behaviour could precede the development of specialised fangs that refine the action.

In conclusion, the spitting ability of the specimen examined here occurs despite the fang morphology and discharge orifice being similar to those of non-spitting cobras, and to enable venom spitting, a spitting manoeuvre is employed. Further investigation is required to establish the nature and frequency of this behaviour in the Chinese cobra in general, with particular attention as to whether such behaviour occurs in the wild. This research also raises a more fundamental question, specifically whether venom spitting can be an individually learned defence behaviour?

\section{ACKNOWLEDGEMENTS}

My thanks go to Peter Zürcher who in 2012 captive bred the specimen used in this study at the Reptilienzoo Nockalm (Patergassen - Austria). A very special thanks also goes to Luca Palazzese, Pasqualino Loi and Pietro Loi for their time and their help at the research labs of the Faculty of Veterinary Medicine of the University of Teramo. I am especially thankful to Rainer Fesser for his help, advice and review and for suggestions and critical review from an anonymous reviewer and Rick Hodges.

\section{REFERENCES}

Bogert, C.M. (1943). Dentitional phenomena in cobras and other elapids, with notes on the adaptive modification of their fangs. Bulletin of the American Museum of Natural History 81: 285-360.

Boie, F. (1827). Bemerkungen über Merrem's Versuch eines Systems der Amphibien, 1. Lieferung: Ophidier, Isis van Oken 20: 508-566.

Cantor, T.E. (1842). General features of Chusan, with remarks on the flora and fauna of that island. Annals and Magazine of Natural History 1: 265-277.

Eichwald, E. (1831). Zoologia specialis quam expositis animabilus tum vivis, tum fossibilus potissimum Rossiae in universum, et Poloniae in species, in usum lectionum publicarum in Universitate Caesareae Vilnensi habendarum. Part 3. Josephi Zawadski, Vilnius.

Fung, H.T., Lam, K.K., Wong, O.F. and Lam, T.S.K. (2010). "Local antivenom Treatment for Ophthalmic Injuries caused by a Naja atra," Journal of Medical Toxicology 6: 147-149.
Herklots, G.A.C. (1938). Land snakes of Honk Kong. Part IV. Naja (the cobras). Hong Kong Natural 8: 189-200.

Karsen, S.J., Lau M.W. \& Bogadek, A. (1986). Hong Kong amphibians and reptiles. Urban Council Publications, Hong Kong.

Lesson, R.P. (1831). Catalogue des reptilesqui font partie d'une collection zoologique recueillie dans I'Inde cntinentale ou en Afrique et rapportée en France par M. Lamare-Piquot. Bullettin of the Museum of Comparative Zoology 95: 121-247.

Linnaeus, C. (1758). Systema Naturae per Regna Tria Naturae secundum Classes, Ordines, Genera, Species cum Characteribus Differentiis, Synonymis, Locis. Laurentii Salvii, Stockholm.

Rasmussen, S., Young, B. \& Krimm, H. (1995). On the 'spitting' behaviour in cobras (Serpentes: Elapidae). Journal of Zoology 237: 27-35.

Reitinger, F.F. \& Lee, J.K.S. (1978). Common snakes of southeast Asia and Hong Kong. Heinemann, Hong Kong, Singapore, Kuala Lumpur.

Santra, V. \& Wüster, W. (2017). Naja Kaouthia (Monocled Cobra). Behavior / spitting. Herpetological Review 48: 455-456.

Triep, M., Hess, D., Chaves, H., Brücker, C., Balmert, A., Westhoff, G. \& Bleckmann, H. (2013). 3D Flow in the Venom Channel of a Spitting Cobra: Do the Ridges in the Fangs Act as a Fluid Guide Vanes? PLoS ONE 8: e61548.

Wallach, V., Wüster ,W. \& Broadley ,D. (2009). In praise of subgenera: taxonomic status of cobras of the genus Naja Laurenti (Serpentes: Elapidae). Zootaxa 2236: 26-36.

Wüster, W. (1996). Taxonomic changes and toxinology; systematic revisions of the Asiatic cobras (Naja naja species complex). Toxicon 34: 399-406.

Wüster, W. \& Thorpe, R.S. (1992). Dentitional phenomena in cobras revisited: Spitting and fang structure in the asiatic species of Naja (Serpentes: Elapidae). Herpetologica 48: 424-434.

Young, B.A. \& O'Shea, M. (2005). Analyses of venom spitting in African cobras (Elapidae: Serpentes). African Zoology 40: 71-76.

Young, B.A., Dunlap, K., Koenig, K. \& Singer, M. (2004). The buccal buckle; the functional morphology of venom spitting in cobras. The Journal of Experimental Biology 207: 3483-3494.

Young, B.A., Boetig, M. \& Westhoff, G. (2009). Spitting behavior of hatchling red spitting cobras (Naja pallida). Herpetological Journal 19: 185-191.

Accepted: 1 June 2019

Please note that the Supplementary Material for this article is available online via the Herpetological Bulletin website: https://thebhs.org/publications/the-herpetological-bulletin/issue-number-148-summer-2019 